\title{
Improving Robustness of Data Network Using Intelligent Modulation Technique
}

\author{
Aneke Israel Chinagolum ${ }^{1}$, Chineke Amaechi Hyacenth ${ }^{2}$, Udeh Chukwuma Callistus. $\mathbf{W}^{3}$ \\ ${ }^{1}$ Computer Science Department, Institute of Management and Technology Enugu, Enugu, Nigeria \\ ${ }^{2}$ Computer Engineering Department, Micheal Okpara University of Agriculture Umudike, Abia, Nigeria \\ ${ }^{3}$ ICT Department, Enugu State University of Science and Technology Teaching Hospital, Enugu, Nigeria
}

\begin{abstract}
The problem of not having a reliable communication network has arisen as a result of robustness of the network which emanate to having high bit error rate, congestion and fading. This can be overcome by characterizing a typical broadband data networks, designing a Simulink model of the network of study and use it to study the extent of robustness of data in the network, evaluating the behavior of packets in the channel network, designing an adaptive modulation scheme to improve robustness in the data network, simulating the above using MATLAB Simulink, designing a visual basic model for improving the robustness of data network using adaptive modulation technique and evaluating and analyzing $S$ the performance of the adaptive modulation for improved robustness to ensure the model developed achieved the research objective. The reduction of robustness in data obtained using adaptive modulation is about $50 \%$ better than using the conventional method. With this result it shows that to enhance free communication network adaptive modulation most be incorporated to reduce the robustness of the network.
\end{abstract}

Keywords: robustness, intelligent, modulation

\section{INTRODUCTION:}

The nonconsistence of free network that has emanated as a result of the network notwithstanding the stress that has arisen as a result of high bit error rate that caused congestion and interference thereby reducing the rate of transporting data from one point to the other in the communication network has lured the researcher to source for a means of overcoming this uncertainty. In the field of communication, wireless communication is the fastest growing technology and the growth of the cellular system is exponential over the last decade. Wireless systems have the capacity to cover broad geographical areas, and it excludes the more costly infrastructures to deploy wired links to the individual sites. The main purpose of broadband wireless communication is to provide reliable and high data rate transmission over a larger area. The first generation of mobile telecommunication technology was analogue and it was introduced in the 1980 's mainly for voice services communication only. Second generation (2G) mobile telecommunication technology was digital and was introduced in 1990, with increased features to provide voice services and basic data transmission services. To support more multimedia services like video messaging and to provide improved quality of service and higher data rates compared to second generation mobile telecommunications, third generation technology is digital, with the capability to provide various forms of multimedia services like video telephoning, good quality of services and can be used anywhere in the world. It has higher data transmission rates enhanced features for more efficient use of the precious spectrum resources compared to $2 \mathrm{G}$. $3 \mathrm{G}$ mobile telecommunication can provide higher data rates of about $384 \mathrm{kbps}$ to $2 \mathrm{Mbps}$ compared to GSM (Global systems for mobile communication) network that is offering between $10 \mathrm{kbps}$ only. The field of wireless communications is developing at faster rate, covering many technical areas and it has a wide influence on various aspects of human endeavor. At the end of 2011, worldwide cellular subscription passed 6 billion and the rapid growth is expected to last for many years. The worldwide activities in this fast growing industry are perhaps an indication of its importance to human development. The growth of this industries has exceeded all estimates and forecasts. Indeed the 
question has not been where the demand is, but instead the question has been how the demand of subscribers can be met. With the demand for mobile communication services increasing at an exponential rate there is a need to increase capacity, extend coverage and improve transmission quality for network providers to effectively accommodate the increased traffic in their network and to satisfy customer expectations.

\subsection{Statement of the Problem}

The cause of the network not withstanding stress has arisen as a result of not having free communication network caused by high bit error rate, interference and congestion. The communication network not being free has made some communication companies to lose some of their subscribers. This will make the concerned networks to sack some of their staff because they cannot meet to paying them salaries. These staff that were sacked might be the pillar of their respective families financially. On the other hand, investors will not have the urge to invest because of poor communication network. If these problem of not having free communication network is solved by improving the robustness of data network using adaptive modulation technique these human agony like sacking staff mentioned herein will be minimized.

The cause of poor communication network is because of high bit error rate that cause interference, congestion, thereby causing a big stress from transmitting packet from one point to the other.

Communication industries have being encountering a lot of problems in their communication links. Some of such difficulties or problems are interference, fading, overhang, congestion and attenuation.

These unfortunate situations have made the passage of piece of information from one point to another or from source to sink difficult. This will equally reduce their output to $40 \%$ thereby discouraging customers not to be subscribing their network. This ugly condition will equally discourage investors from building factories, industries and such communication industries will equally reduce drastically. The mobile radio network must provide a system with improved performance by increasing the network capacity and this requires the proposed technique. The model will be simulated using the result of the analysis of the system. Consequently, if enhancing the channel capacity of a cellular mobile system using frequency diversity is incorporated in our communication industries their output will increase to $20 \%$.

\section{2. literature review}

Many impeccable authors have researched and written on it, but with different approaches. Some of these authors are (Duman, 2015) Time A. Ghrayeb, Block "Space Codes," in Co Communication Systems,(Liu, 2014) Time Coding B for. Broadband Muquet, Wireless S. Zho Communication," ( Chidambara, 2014) "History of Communications, (Peter ,2015) "review of wi and MIMO technique," in Cooperative Communication and(Ilan, 2016) "MIMO Architecture for Wireless Volume 10. These authors could only minimize $52 \%$ robustness that cause interference and congestion in the communication network thereby making the network not to be free. This is because they did not incorporate intelligence in their respective works.

\section{Methodology}

This study was carried out with the need to enhanced end user satisfaction as desired by one of the leading cellular network service providers in Enugu, South East, Nigeria. Network used for the experiment was MTN network.

The empirical data was collected from MTN communication network

\section{Measuring the environment description}

This presents all steps towards the actual model design from field measurement. Twelve MTN base stations were visited and measurement were taken, since both urban and sub-urban prediction models are required, the selection of the 12(twelve) representative sites was done in a way to accommodate both environment scenarios in and around the state.

There are 226 MTN Base stations in Enugu state, classified as follows
A. 2G Only
B. $2 \mathrm{G}$ AND $3 \mathrm{G}$ ONLY
91 BASE STATION
C. $3 \mathrm{G} \mathrm{ONLY}$
D. $2 \mathrm{G}$ AND $3 \mathrm{G}$ ONLY
67 BASE STATIONS 10 BASE STATIONS 34 BASE STATIONS

The drive test on received signal strength on four base stations on each categories where spread to accommodate the classification above when any of the modulation techniques QAM, QPSK and GMSK 
International Journal of Trend in Scientific Research and Development (IJTSRD) ISSN: 2456-6470

are changed at respective base station. RSS measurements up to a distance of 1500 meters were

Gathered in ten (10) sites were both GSM and WCDMA and GSM systems coexist, and two other measurements were taken for CDMA and GSM systems when deployed systems in co-location arrangement, antenna height transmitting power, operating center frequency and locations (Latitude and Longitude) are noted. The measuring Instrument was the transverse electromagnetic wave (TEMS) Investigation Application software programmed in a laptop, sourced from Huawa Technologies (Installers of GSM and CDMA Equipment for both MTN and Visafone).

Table 1: TABLE SHOWING DATA COLLECTION ON PACKET LOSS DUE TO CONGESTION WITH DATE OF DATA COLLECTION: 1 th TO $8^{\text {th }}$ of FEBRUARY, 2018

\begin{tabular}{|c|c|c|c|c|c|c|c|c|c|}
\hline TIME & DAY 1 & DAY 2 & DA Y 3 & DAY 4 & DAY 5 & DAY 6 & DAY 7 & Day 8 & TOTAL \\
\hline 12.00 AM & 5 & 8 & 4 & 8 & 7 & 6 & 5 & 8 & \\
\hline $1.00 \mathrm{AM}$ & 4 & 7 & 6 & 3 & 5 & 7 & 5 & 7 & \\
\hline $2.00 \mathrm{AM}$ & 6 & 5 & 8 & 7 & 5 & 4 & 6 & 5 & \\
\hline $3.00 \mathrm{AM}$ & 8 & 5 & 7 & 8 & 7 & 9 & 10 & 9 & \\
\hline $4.00 \mathrm{AM}$ & 6 & 10 & 8 & 11 & 9 & 12 & 11 & 8 & \\
\hline $5.00 \mathrm{AM}$ & 12 & 11 & 12 & 10 & 14 & 9 & 10 & 13 & \\
\hline $6.00 \mathrm{AM}$ & 18 & 15 & 17 & 19 & 15 & 17 & 18 & 16 & \\
\hline $7.00 \mathrm{AM}$ & 22 & 19 & 20 & 25 & 23 & 22 & 24 & 21 & \\
\hline $8.00 \mathrm{AM}$ & 30 & 35 & 33 & 30 & 40 & 42 & 39 & 37 & \\
\hline $9.00 \mathrm{AM}$ & 49 & 52 & 55 & 50 & 53 & 51 & 54 & 53 & \\
\hline $10.00 \mathrm{AM}$ & 33 & 38 & 40 & 37 & 35 & 40 & 43 & 39 & \\
\hline $11.00 \mathrm{AM}$ & 29 & 31 & 27 & 33 & 30 & 29 & 28 & 33 & \\
\hline $12.00 \mathrm{PM}$ & 22 & 26 & 21 & 23 & 25 & 22 & 23 & 25 & \\
\hline $1.00 \mathrm{PM}$ & 30 & 34 & 32 & 31 & 33 & 35 & 38 & 36 & \\
\hline $2.00 \mathrm{PM}$ & 45 & 40 & 50 & 55 & 49 & 53 & 48 & 52 & \\
\hline $3.00 \mathrm{PM}$ & 19 & 24 & 22 & 26 & 20 & 24 & 21 & 23 & \\
\hline $4.00 \mathrm{PM}$ & 28 & 27 & 30 & 29 & 33 & 28 & 31 & 32 & \\
\hline $5.00 \mathrm{PM}$ & 55 & 50 & 53 & 57 & 51 & 49 & 52 & 56 & \\
\hline $6.00 \mathrm{PM}$ & 48 & 52 & 47 & 50 & 49 & 44 & 48 & 51 & \\
\hline $7.00 \mathrm{PM}$ & 30 & 28 & 33 & 29 & 31 & 35 & 32 & 31 & \\
\hline $8.00 \mathrm{PM}$ & 18 & 22 & 19 & 21 & 20 & 25 & 23 & 22 & \\
\hline $9.00 \mathrm{PM}$ & 14 & 12 & 15 & 18 & 16 & 13 & 15 & 14 & \\
\hline $10.00 \mathrm{PM}$ & 12 & 9 & 11 & 13 & 11 & 9 & 10 & 11 & \\
\hline $11.00 \mathrm{PM}$ & 8 & 7 & 6 & 5 & 7 & 9 & 8 & 6 & \\
\hline TOTAL & 452 & 595 & 576 & 734 & 548 & 594 & 602 & 578 & \\
\hline
\end{tabular}

Table 2: Table showing data collection on packet loss for eight days with congestion

\begin{tabular}{|c|c|}
\hline $\begin{array}{c}\text { Total packet loss } \\
\text { for eight days }\end{array}$ & $\begin{array}{c}\text { Congestion experienced } \\
\text { for the eight days }\end{array}$ \\
\hline 452 & 0.07681 \\
\hline 595 & 0.06695 \\
\hline 576 & 0.2111 \\
\hline 734 & 0.06027 \\
\hline 548 & 0.06976 \\
\hline 594 & 0.21116 \\
\hline 602 & 0.066555 \\
\hline 578 & 0.06793 \\
\hline
\end{tabular}

The mathematical model for improving the robustness of data network using adaptive modulation technique is as shown in equation 3.2

$\mathrm{L}=8 / 3 \mathrm{~W}^{\wedge} 2$

Where $\mathrm{L}$ is packet loss

$\mathrm{W}$ is the network congestion

Then, make $\mathrm{W}$ the subject formula in equation 1

The mathematical model for congestion in the network is as shown in equation 3.2

$\mathrm{W}=$ Square root of $8 / 31$ 
To find the network congestion in day one

$\mathrm{W} 1=$ square root $8 / 3 \times 452$

$\mathrm{W} 1=$ square $\operatorname{root} 8 / 1356=0.07681$

Congestion in day two

$\mathrm{W} 2=$ square $\operatorname{root} 8 / 3 \times 595=8 / 1785=0.0044818$

$\mathrm{W} 2=$ square root of 0.0044818

$\mathrm{W} 2=0.06695$

Congestion in day three

$\mathrm{W} 3=$ Square root of $8 / 3 \times 576$

$\mathrm{W} 3=$ square root of $8 / 1728=0.04456$

$\mathrm{W} 3=$ Square root of $0.04456=0.2111$

Congestion in day four

$\mathrm{W} 4=$ Square root of $8 / 3 \times 734$

$\mathrm{W} 4=$ square root of $8 / 2202$

$\mathrm{W} 4=$ Square root of 0.003633

$\mathrm{W} 4=0.06027$

Congestion in day five

$\mathrm{W} 5=$ square root of $8 / 3 \times 548$

$\mathrm{W} 5=$ Square root of $8 / 1644$

$\mathrm{W} 5=$ Square root of 0.004866

$\mathrm{W} 5=0.06976$

Congestion in day six

$\mathrm{W6}=$ Square root 8/3 5594

$\mathrm{W6}=$ Square root $8 / 1782$

$\mathrm{W} 6=$ Square root 0.04489

$\mathrm{W} 6=0.21116$

Congestion in seventh day

$\mathrm{W} 7=$ Square root $8 / 3 \times 602$

$\mathrm{W} 7=$ Square root $8 / 1806$

$\mathrm{W} 7=$ Square root 00044296

$\mathrm{W} 7=0.066555$

Congestion in day eight

$\mathrm{W} 8=8 / 3 \times 578$

$\mathrm{W} 8=8 / 1734$

$\mathrm{W} 8=$ square root of 0.004614

$\mathrm{W} 8=0.06793$

To determine an ideal bit error rate convenient for the characterized network

Taking into consideration the worst case scenario, the linear relationship between BER and packet error rate (PER) is expressed as:
Where the MTU is the maximum transmission unit, and using the Ethernet standards it is set to 1500 bytes for the simulations and then the MTU is increased to improve performance. A conversion from 8 bits to 1 byte is shown,

Recall 1 byte $=8$ bits

$$
1500 \text { bytes }=8 \times 1500=12000 \text { bits }
$$$$
\text { MTU }=12000 \mathrm{bits}
$$

PER is packet loss and BER is bit error rate

To evaluate the bit error rate in day one when the packet loss is 452

Make BER the subject formula in equation 3

BER1 = PER $/ 8 \times$ MTU $\times 1.03125$-----------------4

$\mathrm{BER} 1=452 / 8 \times 12000 \times 1.03125$

BER1 $=452 / 9900$

BER1 $=0.0457$ bits

To find the bit error rate in day two

BER2 $=595 / 9900$

BER2 $=0.0601$

Bit error rate in day three

BER3 = 576/9900

$\mathrm{BER3}=\mathbf{0 . 0 5 8 2}$

Bit error rate in day four

BER4 = 734/9900

BER4 $=0.0741$ bits

Bit error rate in day five

BER5 $=$ 548/9900

BER5 $=0.0554$ bits

Bit error rate in day six

BER6 = 594/9900

BER6 = 0.06 bits

Bit error rate in day seven

BER7 $=602 / 9900$

BER7 $=0.0608$

Bit error rate in day eight

BER8 = 578/9900

BER8 $=0.0584$ bits

$\mathrm{PER}=8 \times \mathrm{BER} \times \mathrm{MTU} \times$ 66/64----------------------3 
International Journal of Trend in Scientific Research and Development (IJTSRD) ISSN: 2456-6470

Table 3: Table showing data collection on packet loss for eight days with congestion and bit error rate

\begin{tabular}{|l|l|l|l|}
\hline Total packet loss for eight days & Congestion experienced for the eight days & Bit error rate \\
\hline
\end{tabular}

\begin{tabular}{|c|c|c|}
\hline 452 & 0.07681 & 0.0457 bits \\
\hline 595 & 0.06695 & 0.0601 \\
\hline 576 & 0.2111 & 0.0582 \\
\hline 734 & 0.06027 & 0.0741 bits \\
\hline 548 & 0.06976 & 0.0554 bits \\
\hline 594 & 0.21116 & 0.06 bits \\
\hline 602 & 0.066555 & 0.0608 \\
\hline 578 & 0.06793 & 0.0584 bits \\
\hline
\end{tabular}

3.2 To design a Simulink model of the network of study and use it to study the extent of robustness of data in the network

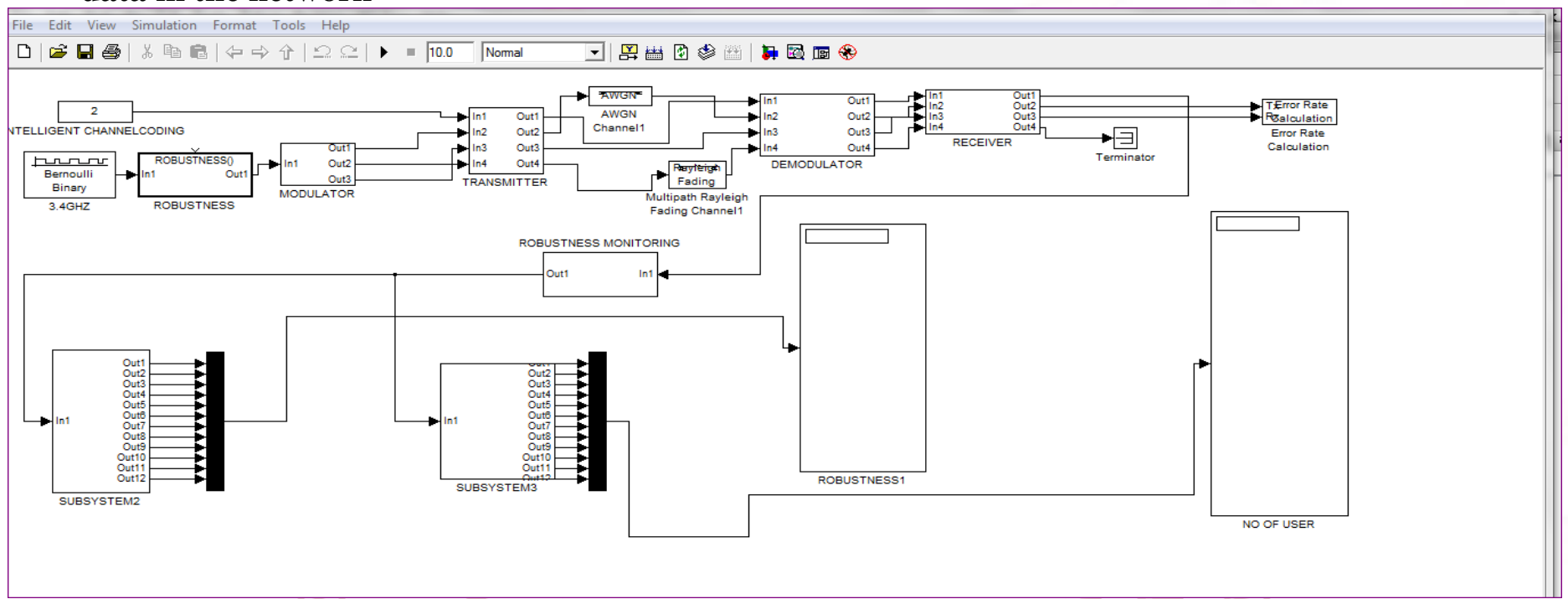

Fig 1 designed Simulink model of the network of study and use it to study the extent of robustness of data in the network

Fig 1 shows designed Simulink model of the network of study and use it to study the extent of robustness of data in the network

This is designed in the Simulink environment with the following Simulink model block robustness block, modulator, transmitter, and demodulator. The empirical or measured data was incorporated in the model.

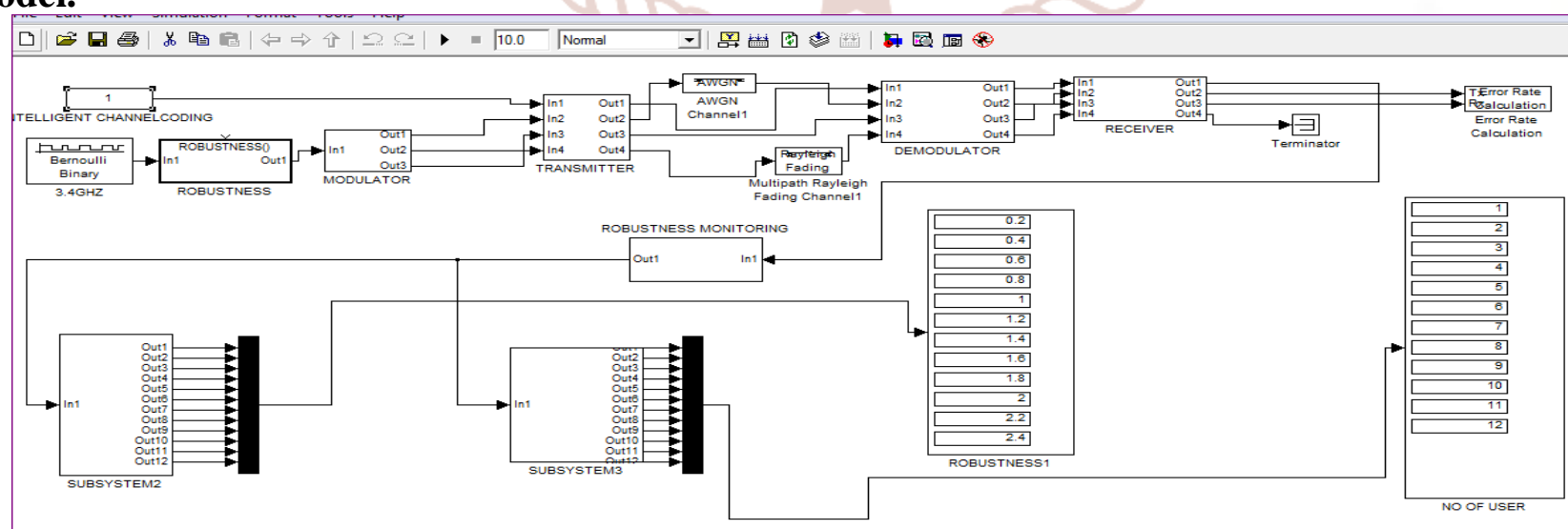

Fig 2 Result of designed Simulink model of the network of study and to study the extent of robustness of data in the network. 
International Journal of Trend in Scientific Research and Development (IJTSRD) ISSN: 2456-6470

Fig 2 shows result of designed Simulink model of the network of study and use it to study the extent of robustness of data in the network. The result of the robustness is detailed in section 4.0.

\subsection{Evaluatetion of the behavior of packets in the channel network.}

The evaluated result shows that as the packet loss increases there will be an increase in congestion and bit error rate concurrently. This result will be incorporated in the Simulink model to check its level of improvement in terms of reducing the bit error rate, congestion and stress in the network.

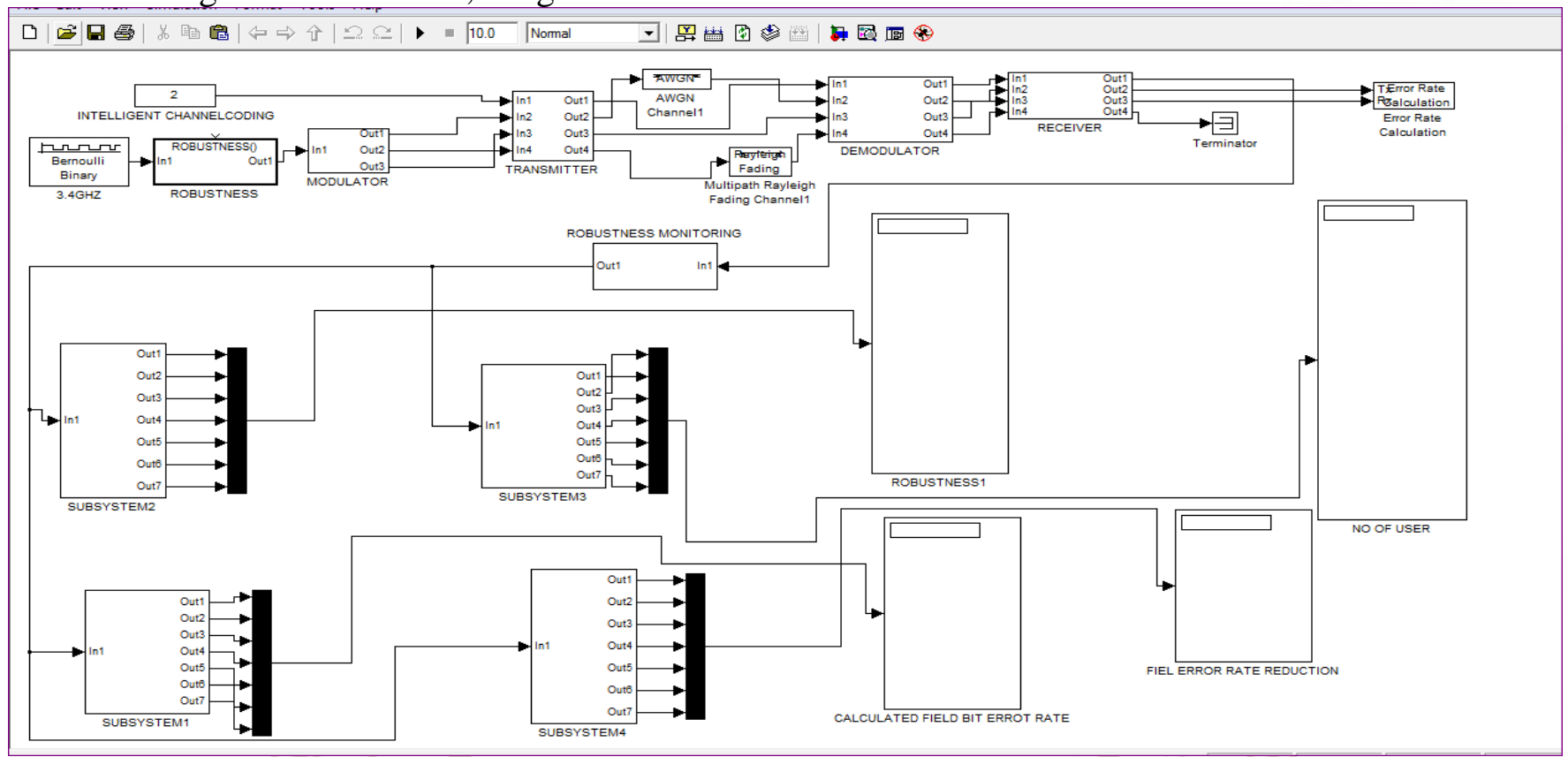

Fig 4 designed adaptive modulation scheme to improve robustness in the data network

Fig 4 shows designed adaptive modulation scheme to improve robustness in the data network

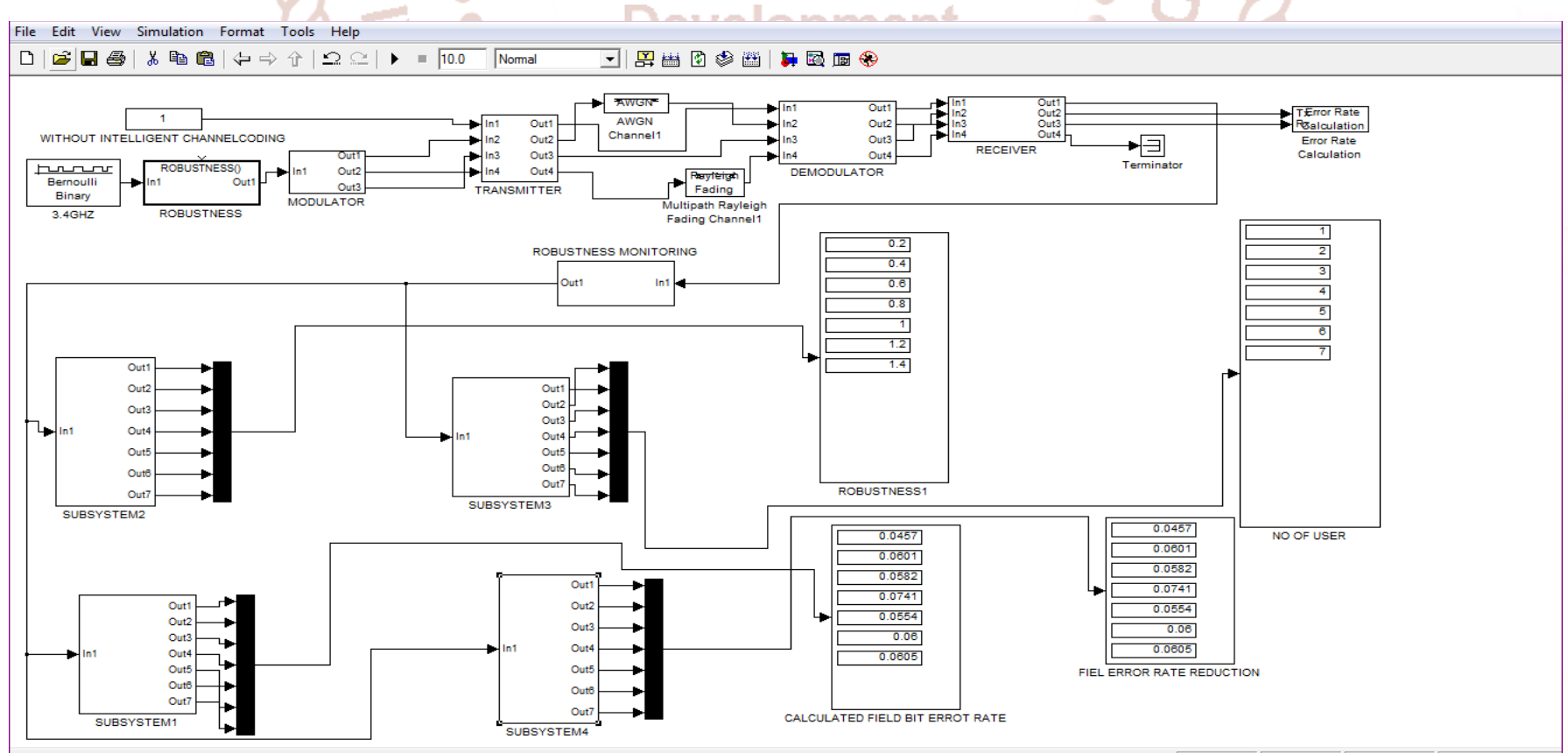

Fig 5 Simulated result for designed scheme to improve robustness in the data network without using adaptive modulation.

Fig 5 shows simulated result for designed scheme to improve robustness in data network without using adaptive modulation. The analysis of the result is shown in fig 4.1. 


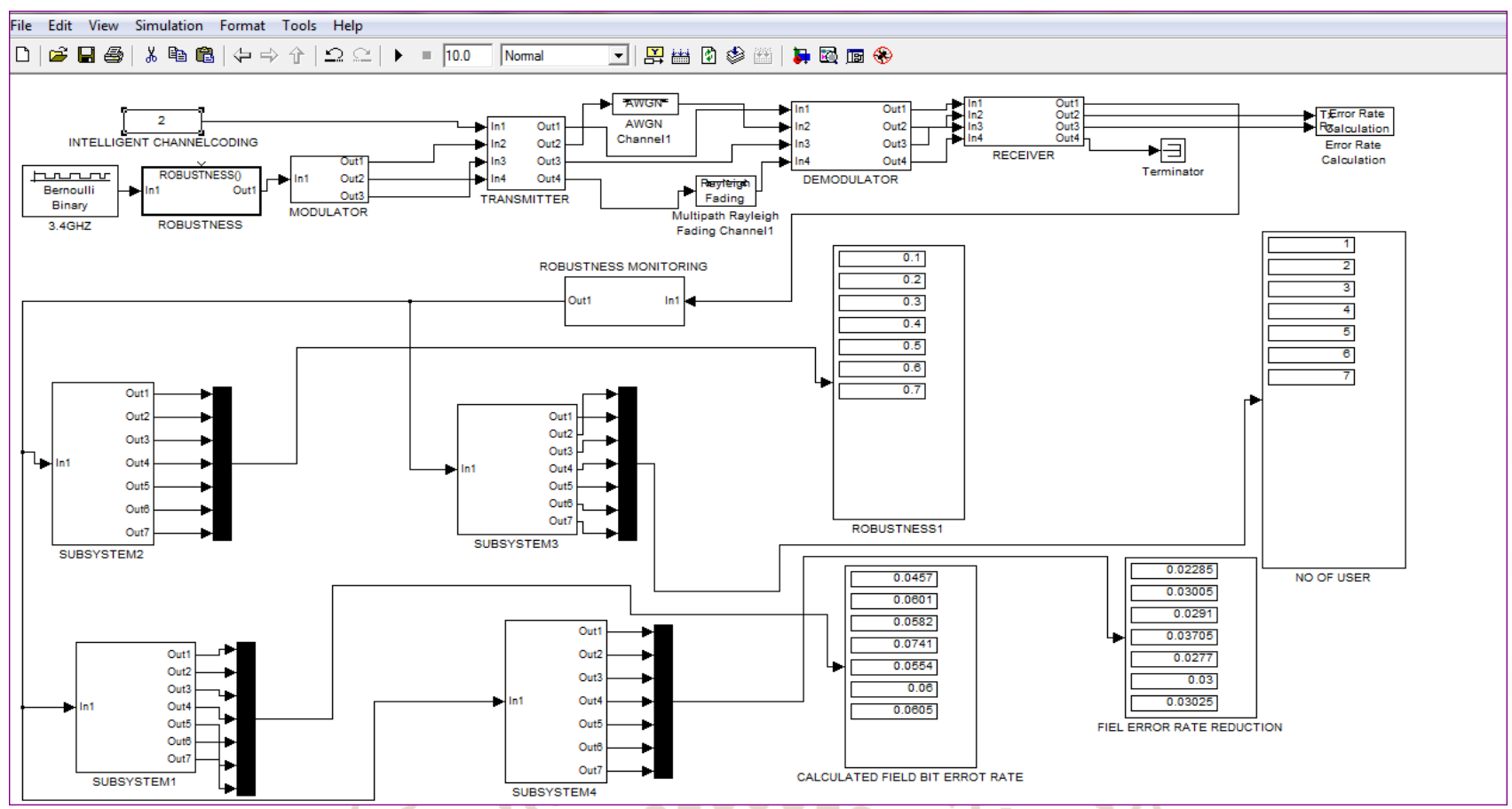

Fig 6 designed adaptive modulation scheme to improve robustness in the data network

Fig 6 shows designed adaptive modulation scheme to improve robustness in the data network. Comparing the result gotten in figures 5 and 6 it is known that the rate of robustness in the communication network is less when adaptive modulation is incorporated in the model.

\section{Result Analysis}

Table 4 FIELD ROBUST VS NO OF USERS

\begin{tabular}{|c|c|}
\hline NO OF USERS & FIELD ROBUST \\
\hline 1 & 0.2 \\
\hline 2 & 0.4 \\
\hline 3 & 0.6 \\
\hline 4 & 0.8 \\
\hline 5 & 1 \\
\hline 6 & 1.2 \\
\hline 7 & 1.4 \\
\hline
\end{tabular}

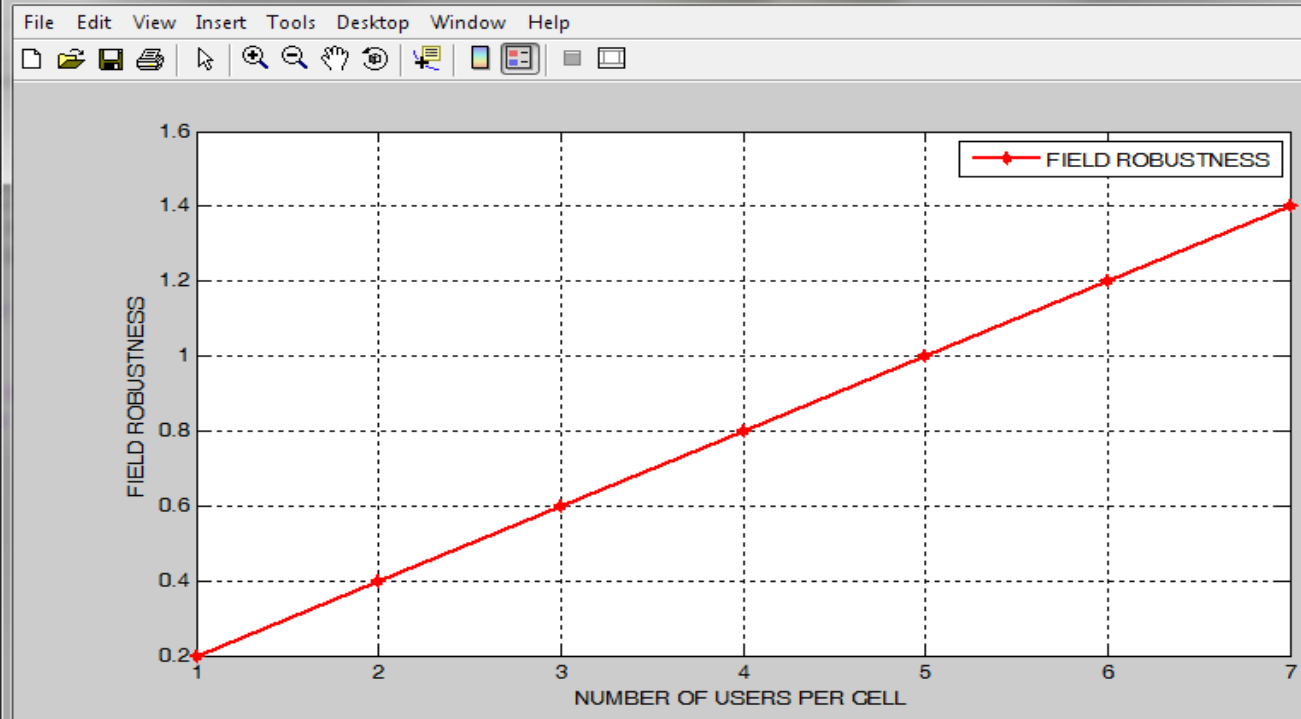

FIG 6 FIELD ROBUST VS NO OF USERS 
Fig 6 shows field robustness vs no of users. The result shows that there is highest robustness at 1.4 when adaptive modulation is not imbibed in the model. With this result it shows that there is interference and congestion in the communication network. This definitely shows that the passage of piece of information from source to sink would not be freely transmitted.

Table 5 Adaptive robust vs No of users

\begin{tabular}{|c|c|}
\hline NO OF USERS & ADAPTIVE ROBUST \\
\hline 1 & 0.1 \\
\hline 2 & 0.2 \\
\hline 3 & 0.3 \\
\hline 4 & 0.4 \\
\hline 5 & 0.5 \\
\hline 6 & 0.6 \\
\hline 7 & 0.7 \\
\hline
\end{tabular}

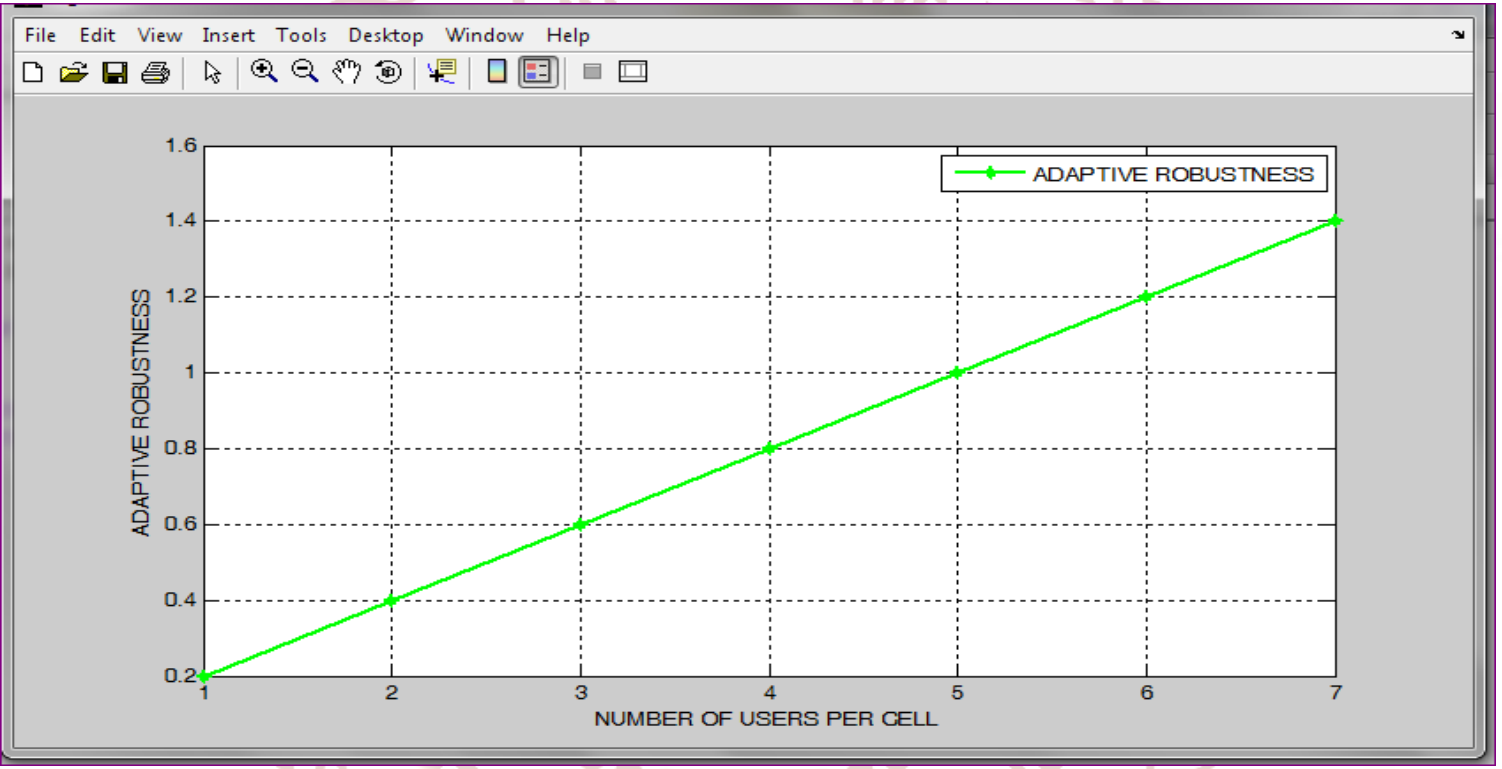

Fig 7 Adaptive robust vs No of users

Fig 7 shows that there is a reduction in rate of robustness when adaptive modulation is incorporated in the network. This will definitely enhance the efficiency of transmitting piece of information from the sender to the receiver without hitch like interference, congestion, fading, high bit error rate etc.

Table 6 Comparing field robust and adaptive robust

\begin{tabular}{|c|c|c|}
\hline NO OF USERS & FIELD ROBUST & ADAPTIVE ROBUST \\
\hline 1 & 0.2 & 0.1 \\
\hline 2 & 0.4 & 0.2 \\
\hline 3 & 0.6 & 0.3 \\
\hline 4 & 0.8 & 0.4 \\
\hline 5 & 1 & 0.5 \\
\hline 6 & 1.2 & 0.6 \\
\hline 7 & 1.4 & 0.7 \\
\hline
\end{tabular}




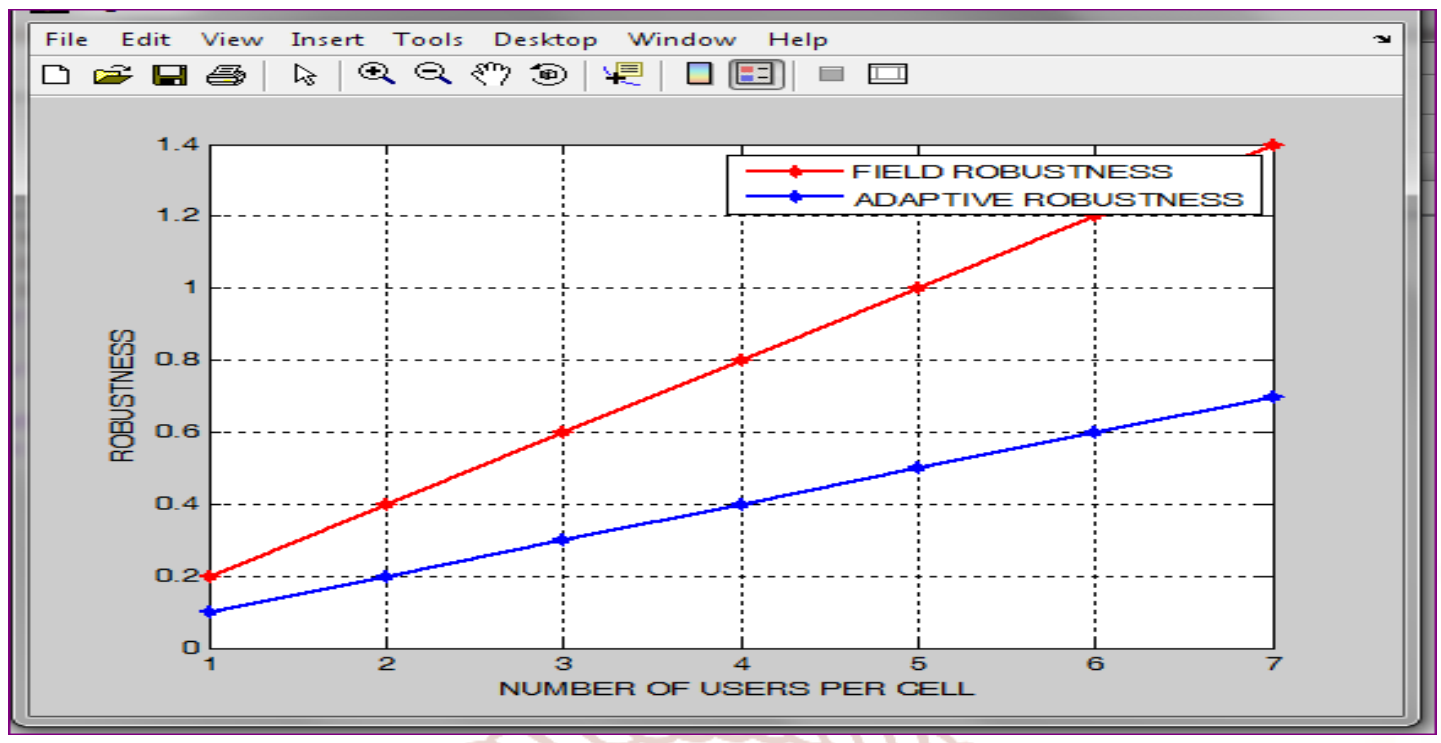

Fig 8 Comparing field robust and adaptive robust

Fig 8 shows the comparing of field robust and adaptive robust. The result in fig 8 above shows that the rate of robustness decreases when adaptive modulation is used.

\section{Conclusion}

The lack of free communication network has arisen as a result of congestion, interference and robustness or stress. This can be overcome by improving the robustness of data network using adaptive modulation technique. It can be done in this manner, characterizing a typical broadband data networks, designing a Simulink model of the network of study and use it to study the extent of robustness of data in the network, evaluating the behavior of packets in the channel network, designing an adaptive modulation scheme to improve robustness in the data network and simulating and comparing the degree of robustness when conventional and adaptive approach is used.

\section{References}

1. T. M. Duman, -Time A. Ghrayeb, Block "Space Codes," in Co Communication Systems, John Wiley and Sons, 2015, PP.71-72

2. T. M. Duman, A. Ghrayeb, "Need for MIMO Communication Systems, John Wiley and Sons, 2015, PP.1-2

3. Z. Liu, G. B. Giannakis, - Time Coding B for. Broadband Muquet, Wireless S. Zho Communication," USA, 2014.

4. M. S. Ullah, M. J. Uddin, "Performance Using Alamout is Scheme and Maximum Ratio Combining 2016.

5. P. M. Chidambara Nathan, "History of

Communications, PHI Press, PP.1-29(2014)
6. "History and Evolution cations of the mob Businessman Globalization of mobile and Wireless technology, Springer, PP.48-49.

7. Sarkar, Tapan K. Salazar-Palma, Magdalena Multiple Mokole,-Input-Multiple -Eric L Output (MIMO) Antenna Systems," in Physics of Multi anten Processing, Hoboken, NJ, USA ,2014, pp 172-173.

8. Tech Target, (November, 2014). SIMO single input multiple output [online], Available: http://searchmobilecomputing. techtarget.com/definition/SIMO.

9. Y. -W. Peter Hong, Wan-Jen Huang, C. -C. Jay Kuo, "review of wi and MIMO technique," in Cooperative Communication. 26-35.(2015)

10. Erik G larsson, petrestoica, "MIMO informationTime Theory," Block Coding in for Wireless Communication, Cambridge UK, Cambridge University Press, 2014. pp 4-7

11. AvClaude Oestges, Bruno Clerckx, "Brie wireless communications: from real-world propagation to space-time code design, Academic press,2015, pp $1-3$

12. Ilan Hen, "MIMO Architecture for Wireless Volume 10 Issue 02, May 15, 2016.

13. A. Neubauer, J. Freudenberger," in Coding V. Kunn, the 